\title{
BLOOD TRANSFUSION IN CARDIAC SURGERY- NEED TO FOLLOW BASICS!
}

\section{Dr. Nikhil Mudgalkar1}

Department of Anesthesia ,Prathima Institute of Medical Sciences, NagnurRoad,Karimnagar

Address for correspondence : Department Of Anesthesia, Prathima institute of medical sciences, Nagnur road, Karimnagar

Mobile 8019615167

Email :drniks2000@yahoo.com

Keywords: Blood transfusion, cardiac surgery, restrictive.

More and more data is coming in recent times about hazards of blood transfusion. In a landmark TRICC1 trial Euvolemic patients in the intensive care unit (ICU) with $\mathrm{Hb}<9 \mathrm{~g} / \mathrm{dl}$ were randomized to a restrictive transfusion strategy for transfusion of PRBCs (transfused if $\mathrm{Hb}<7 \mathrm{~g} / \mathrm{dl}$ to maintain $\mathrm{Hb}$ between 7 and $9 \mathrm{~g} / \mathrm{dl}$ ) or a liberal strategy (transfused if $\mathrm{Hb}<10 \mathrm{~g} / \mathrm{dl}$ to maintain $\mathrm{Hb}$ $10-12 \mathrm{~g} / \mathrm{dl}$ ). Mortality was similar in both groups, indicating that liberal transfusions were not beneficial. An Updated Report by the American Society of AnaesthesiologistsTask Force on Perioperative Blood Management tells us restrictive red blood cell transfusion strategy may be safely used to reduce transfusion administration. It further states that The determination of whether hemoglobin concentrations between 6 and $10 \mathrm{~g} / \mathrm{dl}$ justify or require red blood cell transfusion should be based on potential or actual on going bleeding (rate and magnitude), intravascular volume status, signs of organ ischemia, and adequacy of cardiopulmonary reserve.

Should we extrapolate these guidelines in Cardiac surgery? TRACS2 trial concluded that among patients undergoing cardiac surgery, the use of a restrictive perioperative transfusion strategy compared with a more liberal strategy resulted in noninferior rates of the combined outcome of 30-day all-cause mortality and severe morbidity. They advocated use of restrictive strategy, but 5 years later, the authors 3 concluded that A restrictive transfusion threshold after cardiac surgery was not superior to a liberal threshold with respect to morbidity or health care costs.

With this conflicting evidence, by which way anaesthesiologist to go?

\section{Need to follow basics -}

Till the time guidelines are clearer on this aspect, we can focus more on basics. Perioperative hypothermia leads to coagulopathy, and ultimately, need for blood transfusion. Bleeding observed in low temperature occur because of reduced platelet function as well as reduced activity of coagulation factors. Controllng temperature in operation theatres, use of active warming devices will help us in managing patient temperature in perioperative period.

Maintaining optimal physiologic conditions is another important aspect. Lowph(acidosis) increases blood loss and again anaesthesiologist may need to think of giving blood. Meticulous management of ventilation and end organ perfusion will avoid acidosis and ultimately help us in reducing blood transfusion.

There is a need to maintain ionized calciumabove $1 \mathrm{mmol} /$ litre for adequate platelet function. Careful monitoring of calcium levels and need based treatment to maintain it at higher levels aids in reducing blood loss. 
Finally the meticulous surgical technique: Where surgeon checks all bleeding points carefully is of utmost important. Careful communication with the surgeon and frequent assessment of surgical field can guide us in this aspect.

\section{Conclusion:}

Till the guidelines areclearer, we can focus on basics. Avoidance of hypothermia, acidosis, maintaining normal ionized calcium levels and careful management haemodynamic during perioperative period are critical components of overall patient management.

1. Hébert PC, Wells G, Blajchman MA, Marshall J, Martin C, Pagliarello G. A multicenter, randomized, controlled clinical trial of transfusion requirements in critical care. Transfusion requirements in critical care investigators, Canadian Critical Care Trials Group. N Engl J Med. 1999;340:409-17

2. Hajjar LA, Vincent JL, Galas FR, Nakamura RE, Silva CM, Santos MH, et al. Transfusion requirements after cardiac surgery: The TRACS randomized controlled trial. JAMA. 2010;304:1559-67.

3. Murphy, G.J., Pike, K., Rogers, C.A., Wordsworth, S., Stokes, A., Angelini, G.D. et al. Liberal or restrictive transfusion after cardiac surgery. N Engl J Med. 2015; 372: 997-1008

How to cite the article: MudgalkarN.Blood transfusion in cardiac surgery- need to follow basics! Perspectives in Medical Research 2019; 7(3): 1-2

Sources of Support: Nil, Conflict of interest: None declared 